\title{
Multidimensional Retirement Planning Behaviors, Retirement Confidence, and Post-Retirement Health and Well-Being Among Chinese Older Adults in Hong Kong
}

\author{
Chang Liu ${ }^{1} \cdot$ Xue Bai ${ }^{1,2} \cdot$ Martin Knapp ${ }^{3,4}$
}

Received: 6 May 2020 / Accepted: 13 December 2020/Published online: 29 March 2021

(C) The Author(s) 2021

\begin{abstract}
Maintaining health and well-being in later life is becoming increasingly crucial because of rapid population aging and prolonged years in retirement. Retirement planning may effectively enhance retirement preparedness and confidence and contribute to better post-retirement outcomes. The present study aimed to examine Hong Kong aging adults' engagement in multidimensional retirement planning activities, their retirement confidence, as well as the mediating effects of retirement confidence on the relationships between retirement planning and health and subjective well-being (i.e., physical health, depressive symptoms, and life satisfaction). Face-to-face questionnaire survey was conducted to collect data from 630 retirees aged 50 years and over. The results showed that retirement planning both directly and indirectly influenced physical health, depressive symptoms, and life satisfaction through retirement confidence. Among the four planning subdomains (i.e., financial, health, social life, and psychological planning), health, social life, and psychological planning were found to have positive impacts on physical health and life satisfaction through increased retirement confidence levels, while only social life planning influenced depressive symptoms through retirement confidence. Retirement planning in financial domain was not correlated with retirement confidence but could directly benefit life satisfaction in retirement. The findings reveal the need for the policymakers and service providers to improve public education to raise future retirees' awareness of the importance of retirement planning and promote retirement planning activities, especially social life planning.
\end{abstract}

Keywords Depressive symptoms $\cdot$ Life satisfaction $\cdot$ Retirement confidence $\cdot$ Retirement planning

Xue Bai

xuebai@polyu.edu.hk

Extended author information available on the last page of the article 


\section{Introduction}

Rapid population aging and increased life expectancy have prolonged years in retirement. An increasing number of people, particularly the baby boomer generation worldwide, will enter into the later life stage as they mature and retire. The Census and Statistics Department of Hong Kong (2015) has estimated that in two decades, the aging population will account for $30 \%$ of its whole population. Moreover, residents aged 60 years can expect 25-30 years of retirement on average, which accounts for approximately one-third of the average lifespan (Census and Statistics Department of Hong Kong 2016). Therefore, maintaining health and well-being in later life is becoming increasingly crucial.

A systematic review of research on retirement over the past two decades (Wang and Shultz 2010) revealed that although most retirees are healthy and satisfied with their lives (e.g., Calasanti 1996; Midanik et al. 1995), many of them consider retirement stressful and experience a post-retirement decline in health and well-being (e.g., Kim and Moen 2002; Ross and Drentea 1998). According to role theory, retirement is a transitional process during which people experience work role loss and role transition, and this may cause people to feel anxious and depressed (Ashforth 2001). Moreover, under the construct of role theory, retirement adaptation can be more challenging for older men, because they are traditionally more career-oriented, and work is more central to their identity. Therefore, work role loss may be especially stressful for them (Wang 2007). According to continuity theory (Atchley 1989), maintaining continuity (i.e., consistency in life patterns over time and the accommodation of change without stressful disruption) in identity and self-concept during retirement transition can contribute to smooth retirement adaptation. In other words, if retirees have trouble in maintaining the same lifestyle patterns established prior to retirement, they may experience negative changes in post-retirement well-being. There has been growing concern about retirement adaptation and an increasing number of studies have attempted to identify the protective factors of post-retirement health and well-being.

Retirement planning, defined as "a goal-oriented behavior in which individuals devote effort to prepare for their retirement life" (Yeung and Zhou 2017), can effectively reduce retirement worry, keep stress under control, and enhance retirement preparedness and confidence. According to proactive coping theory (Aspinwall and Taylor 1997), stress can be reduced if the effort is made in advance of a potentially stressful event to prevent it or to modify its form. Therefore, planning is a vital step in effective proactive coping (Bode et al. 2006). Empirical studies have shown that people who made retirement plans in the final stage of their working life reported lower levels of anxiety and depression during retirement transition than people who did not (Fretz et al. 1989). Moreover, Bandura's (1977) theory of self-efficacy states that the cumulative effort in conducting coping activities can help people gain mastery and a reinforced sense of self-efficacy and their defensive behavior is diminished. Under this theoretical construct, engaging in planning activities can contribute to a person's sense of preparedness and confidence in their ability to make the retirement transition (Taylor-Carter et al. 1997) and help him or her to execute the behavior required to produce desirable outcomes. Collecting information related to an unfamiliar or potentially threatening task can increase a person's confidence in the ability to complete that task (Taylor-Carter et al. 1997). Empirical studies have shown that retirement planning 
activities facilitate more realistic and positive attitudes toward retirement (Mutran et al. 1997; Reitzes and Mutran 2004; Yeung 2013), and higher retirement confidence (Kim et al. 2005; Schellenberg 2004). Moreover, the confident attitude toward retirement is important in adjusting satisfactorily to retirement (Atchley 1991; Kim et al. 2005). Low confidence in handling retirement has been identified as a strong predictor of anxiety and depression in retirees (Fretz et al. 1989).

Researchers have shown that effective retirement planning can contribute to better post-retirement outcomes. For example, Noone et al. (2009) found that people who had discussed retirement with their spouses and had superannuation or savings plans reported greater retirement satisfaction and physical and emotional well-being. In a small-scale longitudinal study, Yeung and Zhou (2017) found that preretirement planning activities are associated with a larger pool of retirement resources at the preretirement stage, which then causes positive changes in psychological well-being and high retirement satisfaction. This finding is consistent with that of Wang (2007), who found that retirees engaging in retirement planning are more likely to experience minimal changes in their psychological well-being during retirement transition than retirees who did not engage in retirement planning.

Retirement planning should be viewed as a multidimensional concept comprising financial, health, social life, and psychological planning (Lee and Law 2004; Yeung 2013). However, some studies have either treated retirement planning as planned retirement age (e.g., Larsen 2008), or used a general item to measure the level of retirement planning such as "How much have you thought about retirement planning?" (e.g., Elder and Rudolph 1999; Kosloski et al. 2001; Quick and Moen 1998). Moreover, many studies have focused exclusively on financial planning (e.g., Hershey et al. 2003; Kim et al. 2005; Lusardi and Mitchell 2011). Taylor-Carter et al. (1997) categorized retirement planning into informal planning (i.e., leisure and financial planning; measured by asking participants to rate their knowledge about financial planning and their expected financial situations after retirement) and formal planning (measured by asking participants whether they have attended a retirement planning seminar). Few studies have tried to use a comprehensive measure that covers common areas of retirement planning, such as finances, activities, work, living arrangements, health, dependents, friends, and household tasks (e.g., Fretz et al. 1989). Studies have reported the potential of retirement planning to improve post-retirement well-being. However, it remains unclear whether different retirement planning activities are associated with post-retirement well-being, and whether and to what extent retirement confidence acts as a mediator in the relationship between retirement planning and post-retirement well-being, and whether sex differences exist in retirement-related experiences.

The present study examined Hong Kong aging adults' engagement in multidimensional retirement planning activities (i.e., financial planning, psychological planning, health planning, and social life planning), their retirement confidence, as well as health and subjective well-being, and investigated sex differences in retirement-related experiences. Moreover, the underlying mechanisms between retirement planning (both in general and in the above mentioned four specific planning domains) and postretirement health and well-being were investigated. Integrating the perspectives of proactive coping theory (Aspinwall and Taylor 1997), self-efficacy theory (Bandura 1977), and empirical evidence, a conceptual framework was developed to guide this 
study (Fig. 1). In this study, it was hypothesized that: (H1) more active engagement in preretirement planning activities (i.e., financial, health, social life, psychological, and care planning) generates a higher level of retirement confidence, $(\mathrm{H} 2)$ thereby a higher level of retirement confidence produces better post-retirement health and well-being outcomes (i.e., better physical and mental health and greater life satisfaction), and (H3) engagement in retirement planning activities directly produces better post-retirement health and well-being outcomes. Moreover, it was hypothesized that: (H4) men and women have different retirement experiences (both in terms of their focus and effort in retirement planning), and retirement confidence.

\section{Methods}

\section{Participants}

The target population was Chinese older adults 1) aged 50 years or older, 2) residing in Hong Kong (i.e., Hong Kong Island, Kowloon, and New Territories), 3) who spoke Cantonese or Mandarin, and 4) who can answer survey questions. The target sample size was set at 1000. A purposive sampling strategy was used to recruit eligible participants. Researchers went across the 18 districts in Hong Kong to purposefully recruit participants of different sexes and socioeconomic statuses. For example, to ensure sample diversity in terms of socioeconomic statuses, researchers went to both public and private housing estates to approach participants of different economic levels. Participants were also recruited from some social organizations that attracted older adults of certain socioeconomic groups. Concerning the sexes of participants, researchers tried to balance the number of men and women recruited during each trip of data collection. Overall, 1066 older adults were successfully interviewed (538 men and 528 women). Data from 630 retired participants were used for analysis to ensure that all the information collected was based on preretirement and post-retirement experiences.

\section{Data Collection}

For data collection, a face-to-face questionnaire survey was conducted from November 2017 to May 2018. Retrospective measures were used to collect data on the

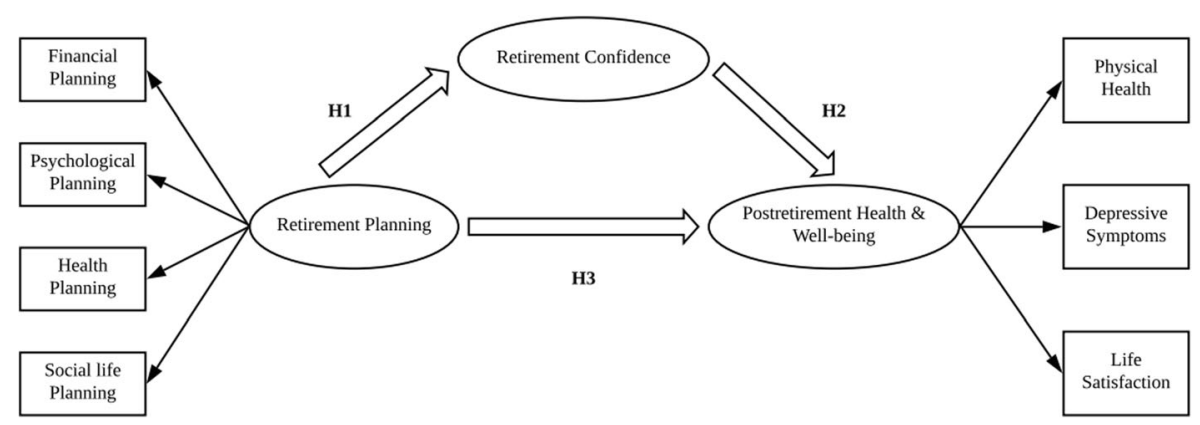

Fig. 1 Guiding conceptual framework 
participants' preretirement planning activities and retirement confidence. Ethical approval was granted by the Human Subjects Ethics Sub-Committee of Hong Kong Polytechnic University. The participants were informed of the objectives of the survey and the voluntary nature of their participation. Prior to interviews, the participants signed consent forms. Two experienced research assistants and five undergraduate students having educational backgrounds in social sciences and possessing good communication skills with older people conducted the interviews. Interview training was provided before and during data collection. Each interview lasted approximately 30 minutes.

\section{Measurement}

\section{Retirement Planning}

Retirement planning behaviors were measured using a locally developed and validated scale of retirement planning activities (Law et al. 2006; Yeung 2013; Yeung and Zhou 2017). The scale comprised a set of 20 dichotomous items that measured four domains of retirement planning, namely financial planning (five items; e.g., "set up a separate savings account for retirement"), health planning (four items; e.g., "exercise at least three times a week"), social life planning (four items; e.g., "cultivate enjoyable hobbies for retirement"), and psychological planning (seven items; e.g., "participated in workshops or seminars on retirement"). The participants reported whether (yes $=1$, no $=0$ ) they had engaged in these planning activities. The total score ranged from 0 to 20 , with a higher score indicating greater retirement planning effort. For our sample, the internal consistency of the scale, which was measured using Cronbach's alpha, was 0.872. For the subscales measuring financial, health, social life, and psychological planning, Cronbach's alpha was $0.707,0.629,0.644$, and 0.791 , respectively.

\section{Retirement Confidence}

Retirement confidence was measured based on the participants' self-perceived level of confidence in the aspects of the sufficiency of income, maintenance of health, and cultivation of enjoyable hobbies (Law et al. 2006; Lee and Law 2004). The fourth question, which measures the participants' confidence in children's support, was deleted in the present study because some of the participants were childless. A 5point scale, ranging from 1 ("not confident at all") to 5 ("very confident"), was used to measure the participants' degree of confidence. The total score ranged from 3 to 15, with a higher score indicating higher retirement confidence. For our sample, the internal consistency of the three-item scale, which was measured using Cronbach's alpha, was 0.786.

\section{Physical Health}

Participants' physical health was measured by the one-item self-rated degree of physical health status. A 5-point scale, ranging from "bad" to "extremely good" was adopted. The total score ranged from 1 to 5 , with a higher score indicating a better physical health status. 


\section{Depressive Symptoms}

The five-item version of the Geriatric Depression Scale (Rinaldi et al. 2003) was used to assess the participants' mental health status. The participants' feelings about their situations were examined through the following descriptions in the questions of the scale: "basically satisfied with life," "often get bored," "often feel helpless," "pretty worthless," and "prefer to stay at home rather than go out and do new things." The first question was related to a positive feeling, whereas questions $2-5$ were related to negative feelings. The participants reported whether (yes $=1$, no $=0$ ) they had experienced such feelings during the previous week. The score of the first item was reverse coded, and the total score ranged from 0 to 5 , with a higher score indicating a worse mental health status. For our sample, the internal consistency of the scale, which was measured using Cronbach's alpha, was 0.728.

\section{Life Satisfaction}

Life satisfaction was measured using the Chinese version of the Satisfaction with Life Scale (Diener et al. 1985; Sun et al. 2014). The participants used a 5-point scale (from $1=$ "strongly disagree" to $5=$ "strongly agree") to indicate their agreement with the following five statements: 1) "In most ways, my life is close to ideal"; 2) "The conditions of my life are excellent"; 3) "I am satisfied with my life"; 4) "So far I have gotten the important things I want in life"; and 5) "If I could live my life over, I would almost change nothing". The total score ranged from 5 to 25 , with a higher score indicating higher life satisfaction. For our sample, the internal consistency of the scale, which was measured using Cronbach's alpha, was 0.924.

\section{Control Variables}

Age, sex, marital status, educational level, having children or not, and functional health status were treated as control variables. The participants were asked about their marital status, which was categorized into "never married," "cohabiting," "married," "separated," "divorced," or "widowed." In the analysis, this item was further coded into 0 ("do not have a partner") or 1 ("have a partner"). Their educational level was rated from 1 ("no formal education") to 10 ("master's degree or above"). The participants were asked whether they had children, and this item was categorized into 0 ("do not have children") and 1 ("have one or more children"). Their functional health status was measured using the Chinese version of the Lawton Instrumental Activities of Daily Living (IADL) scale (Leung et al. 2011). The participants rated their performance in preparing meals, performing ordinary household chores, managing finances, managing medication, using the phone, shopping, and using transport on a 4-point scale ranging from 1 ("no difficulty") to 4 ("unable"). The total scores ranged from 7 to 28 , with a higher score indicating greater functional impairment. For our sample, the internal consistency of the scale, which was measured using Cronbach's alpha, was 0.790 .

\section{Data Analyses}

Data analyses were performed using SPSS (IBM Corp 2016). Descriptive analyses were initially conducted to obtain the mean and standard deviation of each key study 
variable for the entire sample and according to sex. Independent sample $t$-tests were employed to compare the means of the male and female subsamples. Intercorrelations between the study variables were subsequently examined. The mediating effect of retirement confidence on the relationship between the retirement planning total score and health and subjective well-being (i.e., physical health, depressive symptoms, and life satisfaction) were tested using the PROCESS macro in SPSS (Hayes 2013). Subsequently, the mediating effect of retirement confidence on the relationship between the retirement planning four subdomains (i.e., financial, health, social life, and psychological planning) and health and subjective well-being were examined. The total effect (c), direct effect (c'), and bootstrap-based confidence intervals (CIs) of the indirect effect $(\mathrm{ab})$ were calculated using 5000 bootstrap samples. Significant mediating effects are represented by $95 \%$ CIs that did not contain a zero (Mallinckrod et al. 2006).

\section{Results}

Table 1 presents the descriptive statistics of the key variables for the entire sample and by sex. The average age of the 630 participants was 71.713 years. Moreover, $57.9 \%$ were male and $63.5 \%$ had a partner. The mean educational level is 4.432 and the mean score of IADL is 7.465 . The mean score for retirement planning was 4.713 out of 20 , revealing a low level of retirement planning among the participants. The degrees of financial, health, social life, and psychological planning were also low, with mean scores of $1.048,1.585,0.772$, and 1.326 , respectively. The mean score of retirement confidence was 9.939 out of 15 , revealing a moderate level of confidence. The mean scores of physical health, depressive symptoms, and life satisfaction were 2.594 out of $5,0.690$ out of 5 , and 18.080 out of 25 , respectively. The male and female participants showed significant differences in mean age (male: 73.311 ; female: 69.481), having a partner (male: $72.6 \%$; female: $50.9 \%$ ), level of social life planning (male: 0.666; female: 0.923 ), degree of retirement confidence (male: 9.688; female: 10.293), and life satisfaction (male: 17.613; female: 18.732). Table 2 presents the bivariate correlations between the key variables. Physical health, depressive symptoms, and life satisfaction were significantly correlated with retirement planning and its four subdomains as well as retirement confidence. Retirement planning and its four subdomains were all significantly and positively associated with retirement confidence.

Figures 2, 3 and 4 present the mediating role of retirement confidence on the relationships of the total score and different subdomains of retirement planning (i.e., financial, health, social life, and psychological planning) with health and subjective well-being (i.e., physical health, depressive symptoms, and life satisfaction). As shown in Fig. 2, after controlling for age, sex, educational level, marital status, having children or not, and IADL score, the total score of retirement planning had a significant total effect $(B=0.042[0.010], t=4.225, C I[0.022,0.061])$ and indirect effect $(B=0.008$ [0.003], CI [0.003, 0.014]) on physical health, revealing that retirement confidence mediated the relationship between retirement planning and physical health. Additional analyses were performed to investigate whether retirement confidence mediates the relationship between the four retirement planning subdomains and physical health. The results showed that retirement confidence partially mediated the relationship between health, social life, and psychological planning and physical health. However, the total 
Table 1 Descriptive Statistics of Participants' Characteristics

\begin{tabular}{|c|c|c|c|c|}
\hline & \multicolumn{3}{|c|}{ Mean (SD) } & \multirow{2}{*}{$\begin{array}{l}\text { Gender difference } \\
p \text { value }\end{array}$} \\
\hline & $\begin{array}{l}\text { Total } \\
(n=630)\end{array}$ & $\begin{array}{l}\text { Male } \\
(n=365)\end{array}$ & $\begin{array}{l}\text { Female } \\
(n=265)\end{array}$ & \\
\hline Age & $\begin{array}{l}71.713 \\
(9.020)\end{array}$ & $\begin{array}{l}73.311 \\
(8.266)\end{array}$ & $\begin{array}{l}69.481 \\
(9.556)\end{array}$ & $0.000^{* * *}$ \\
\hline Education level & $\begin{array}{r}4.432 \\
(2.473)\end{array}$ & $\begin{array}{r}4.469 \\
(2.345)\end{array}$ & $\begin{array}{c}4.381 \\
(2.643)\end{array}$ & 0.662 \\
\hline Have a partner & $\begin{array}{r}0.635 \\
(0.482)\end{array}$ & $\begin{array}{r}0.726 \\
(0.447)\end{array}$ & $\begin{array}{r}0.509 \\
(0.501)\end{array}$ & $0.000^{* * *}$ \\
\hline IADLs & $\begin{array}{c}7.465 \\
(1.456)\end{array}$ & $\begin{array}{c}7.407 \\
(1.332)\end{array}$ & $\begin{array}{r}7.546 \\
(1.609)\end{array}$ & 0.239 \\
\hline Retirement planning & $\begin{array}{c}4.713 \\
(4.364)\end{array}$ & $\begin{array}{c}4.471 \\
(4.164)\end{array}$ & $\begin{array}{r}5.059 \\
(4.621)\end{array}$ & 0.099 \\
\hline Financial planning & $\begin{array}{c}1.048 \\
(1.358)\end{array}$ & $\begin{array}{c}1.019 \\
(1.325)\end{array}$ & $\begin{array}{r}1.090 \\
(1.404)\end{array}$ & 0.524 \\
\hline Health planning & $\begin{array}{c}1.585 \\
(1.288)\end{array}$ & $\begin{array}{c}1.537 \\
(1.250)\end{array}$ & $\begin{array}{r}1.654 \\
(1.341)\end{array}$ & 0.266 \\
\hline Social life planning & $\begin{array}{c}0.772 \\
(1.033)\end{array}$ & $\begin{array}{r}0.666 \\
(1.010)\end{array}$ & $\begin{array}{c}0.923 \\
(1.048)\end{array}$ & $0.002 * *$ \\
\hline Psychological planning & $\begin{array}{r}1.326 \\
(1.808)\end{array}$ & $\begin{array}{c}1.249 \\
(1.753)\end{array}$ & $\begin{array}{c}1.434 \\
(1.881)\end{array}$ & 0.209 \\
\hline Retirement confidence & $\begin{array}{r}9.939 \\
(2.873)\end{array}$ & $\begin{array}{c}9.688 \\
(2.943)\end{array}$ & $\begin{array}{l}10.293 \\
(2.739)\end{array}$ & $0.009 * *$ \\
\hline Physical health & $\begin{array}{c}2.594 \\
(0.927)\end{array}$ & $\begin{array}{r}2.622 \\
(0.952)\end{array}$ & $\begin{array}{r}2.555 \\
(0.891)\end{array}$ & 0.369 \\
\hline Depressive symptoms & $\begin{array}{c}0.690 \\
(1.034)\end{array}$ & $\begin{array}{r}0.659 \\
(0.970)\end{array}$ & $\begin{array}{c}0.731 \\
(1.117)\end{array}$ & 0.391 \\
\hline Life satisfaction & $\begin{array}{l}18.080 \\
(4.395)\end{array}$ & $\begin{array}{l}17.613 \\
(4.493)\end{array}$ & $\begin{array}{l}18.732 \\
(4.177)\end{array}$ & $0.002 * *$ \\
\hline
\end{tabular}

Standard deviations in parentheses

***indicates significance at $p<0.001$ and $* * p<0.01$

effect $(B=0.058[0.030], t=1.933, C I[-0.001,0.117])$ and indirect effect $(B=0.005$ $[0.008]$, CI $[-0.010,0.021])$ of financial planning on physical health was nonsignificant. Figure 3 shows that the total score of retirement planning had a significant total effect $(\mathrm{B}=-0.026[0.011], \mathrm{t}=-2.295$, CI $[-0.048,-0.004])$ and indirect effect $(\mathrm{B}=$ $-0.014[0.005])$, CI $[-0.024,-0.006])$ on depressive symptoms, revealing the mediating role of retirement confidence on the relationship between retirement planning and depressive symptoms. Retirement confidence also partially mediated the relationship between social life planning subdomain and depressive symptoms, with a significant total effect $(\mathrm{B}=-0.158[0.045], \mathrm{t}=-3.516$, CI $[-0.246,-0.070])$ and indirect effect $(\mathrm{B}=-0.063[0.021]$, CI $[-0.109,-0.026])$ on depressive symptoms. Similar to Fig. 2 , Figure 4 shows that the total score and three subdomains of retirement planning (except financial planning) had significant total and indirect effects on life satisfaction through retirement confidence. 


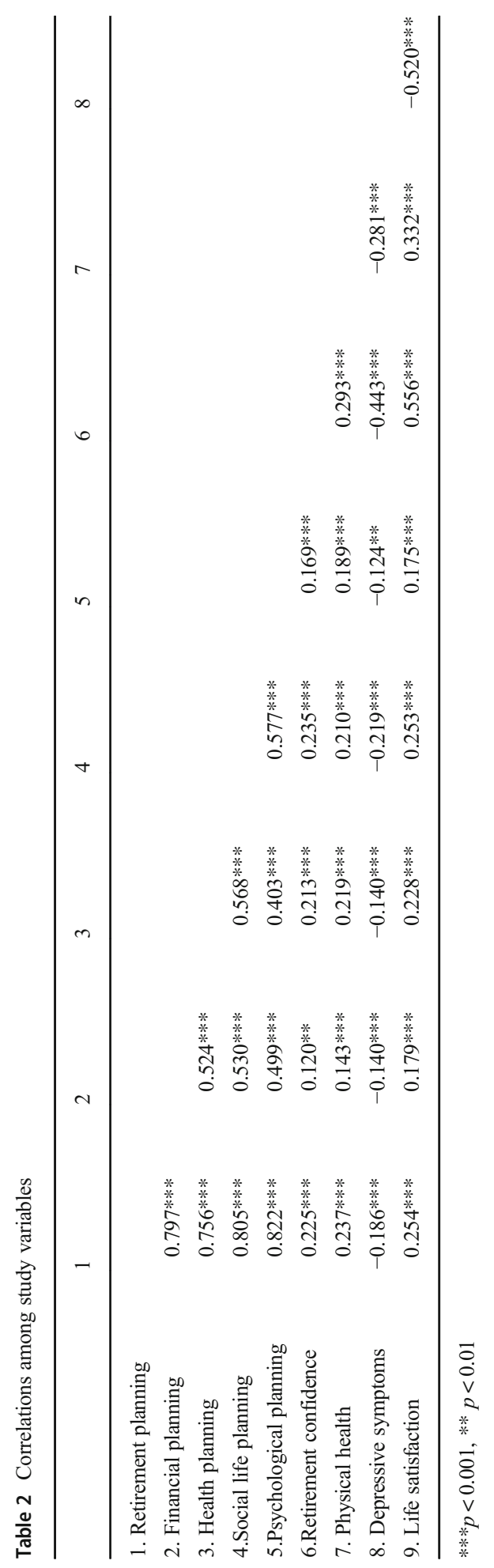




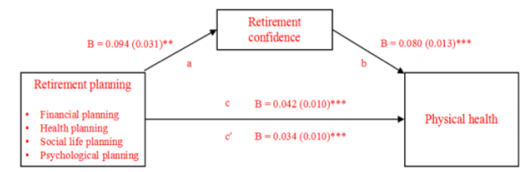

Indirect effect $(\mathrm{ab})=0.008, \mathrm{SE}=0.003, \mathrm{Cl} 95 \%=0.003$ to $0.014 ;$ Coefficients $(\mathrm{SE})$ of covariates age, gender, marital status, education, having children or not, and IADL were $0.002(0.005), 0.031(0.078), 0.036(0.082)$,

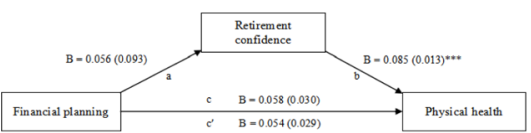

Indirect effect (ab) $=0.005, \mathrm{SE}=0.008, \mathrm{Cl} 95 \%=-0.010$ to 0.021 ; Coefficients (SE) of covariates age, gender, marital status, education, having children or not, and IADL were $0.000(0.005), 0.014(0.079)$,

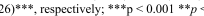

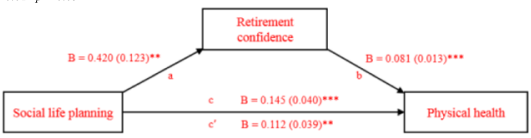

Indirect effect $(\mathrm{ab})=0.034, \mathrm{SE}=0.012, \mathrm{Cl} 95 \%=0.015$ to 0.062 ; Coefficients ( $\mathrm{SE}$ ) of covariates age, gender, marital status, education, having children or not, and IADL were $0.000(0.005), 0.051(0.079)$,
$0.026(0.082), 0.031(0.018),-0.015(0.117)$, and $-0.132(0.025)^{* * *}$, respectively; $* * * \mathrm{p}<0.001 . *{ }^{*} p<$

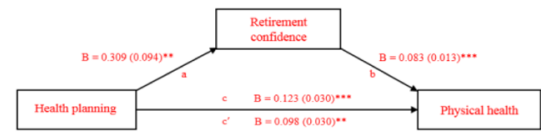

Indirect effect $(\mathrm{ab})=0.025, \mathrm{SE}=0.009, \mathrm{CI} 95 \%=0.010$ to 0.046 ; Coefficients (SE) of covariates age, gender, marital status, education, having children or not, and IADL were $0.000(0.005), 0.024(0.078)$

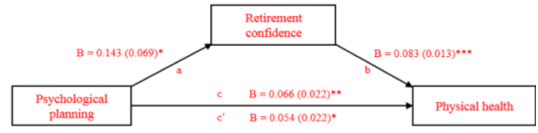

Indirect effect (ab) $=0.012, \mathrm{SE}=0.006, \mathrm{CI} 95 \%=0.002$ to $0.023 ;$ Coefficients (SE) of covariates age gender, marital status, education, having children or not and IADL were $0.001(0.005), 0.021(0.078)$ $0.01 * p<0.05$

Fig. 2 Mediation of different domains of retirement planning and physical health by retirement confidence

\section{Discussion and Implications}

The present study comprehensively examined Hong Kong aging adults' engagement in retirement planning activities in four specific planning domains as well as their level of retirement confidence. This study is the first to examine the mediating role of retirement confidence on the relationship between retirement planning (both in general and in the four subdomains) and post-retirement health and well-being. The results generally supported the hypotheses proposed in this study and revealed that being more engaged in retirement planning could influence post-retirement health and well-being directly,

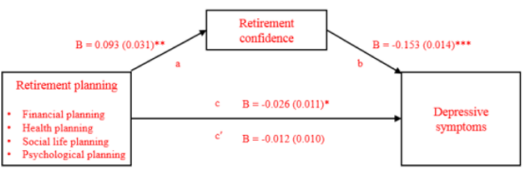

Indirect effect (ab) $=-0.014, \mathrm{SE}=0.005, \mathrm{CI} 95 \%=-0.024$ to -0.006 ; Coefficients (SE) of covariates age, gender, marital status, education, having children or not, and IADL were $-0.005(0.006),-0.038(0.089),-0.187(0.093)$
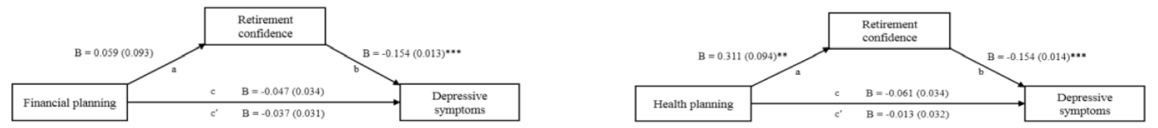

Indirect effect $(\mathrm{ab})=-0.009, \mathrm{SE}=0.014, \mathrm{Cl} 95 \%=-0.035$ to $0.020 ;$ Coefficients $(\mathrm{SE})$ of covariates age, gender, marital status, education, having children or not, and IADL were $-0.003(0.005),-0.027(0.089)$,
$-0.193(0.093)^{*},-0.075(0.020)^{* * * *}, 0.144(0.134)$ and $0.067(0.029)^{*}$, respectively; $* * *^{*}<0.001 *^{* *} p$ $0.01 * p<0.05$

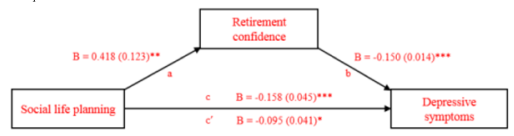

Indirect effect $(\mathrm{ab})=-0.063, \mathrm{SE}=0.021, \mathrm{Cl} 95 \%=-0.109$ to -0.026 ; Coefficients (SE) of covariates age, gender, marital status, education, having children or not, and IADL were $-0.004(0.005),-0.061$ ${ }^{* *} p<0.01{ }^{*} p<0.05$

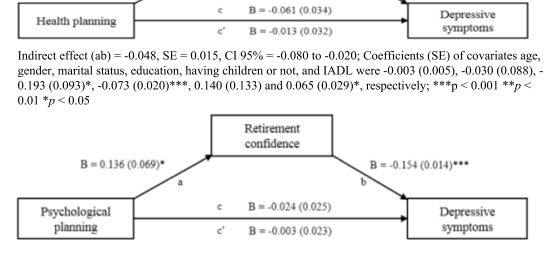

Indirect effect (ab) $=-0.021, \mathrm{SE}=0.010, \mathrm{Cl} 95 \%=-0.043$ to -0.003 ; Coefficients (SE) of covariates age, gender, marital status, education, having children or not, and IADL were $-0.003(0.006),-0.023(0.088),-$
$0.194(0.093)^{*}-0.079(0.020)^{* * *}, 0.133(0.133)$ and $0.065(0.029)^{* *}$ respectively $* * * p<0.001 * *_{p}<0.01$ $0.194(0.053)$

Fig. 3 Mediation of different domains of retirement planning and depressive symptoms by retirement confidence 


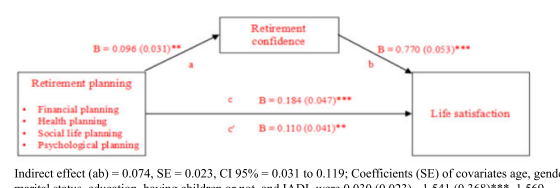

Indirect effect $(\mathrm{ab})=0.074, \mathrm{SE}=0.023, \mathrm{CI} 95 \%=0.031$ to $0.119 ;$ Coefficients $(\mathrm{SE})$ of covariates age, gender,
marital status, education, having children or not, and IADL were $0.030(0.023),-1.541(0.368)^{* * * *}, 1.569$ marital status, education, having children or not, and IADL were $0.030(0.023),-1.541(0.368)^{* * *}, 1.569$
$(0.386)^{* * *}, 0.213(0.086)^{*}, 0.778(0.551)$, and $-0.108(0.119)$, respectively; $* * * \mathrm{p}<0.001 *{ }^{*} p<0.01{ }^{*} p$
0.05

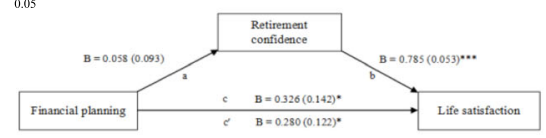

Indirect effect (ab) $=0.046, \mathrm{SE}=0.071, \mathrm{Cl} 95 \%=-0.094$ to 0.185 ; Coefficients (SE) of covariates age, gender, marital status, education, having children or not, and IADL were $0.022(0.023),-1.619(0.370)^{* * *}$,
$1.610(0.389)^{* * *}, 0.290(0.084)^{* *}, 0.841(0.556)$, and $-0.108(0.121)$, respectively; $* * * \mathrm{p}<0.001 * * p<$ $1.610(0.389) * * * 1 * 0$
0.01

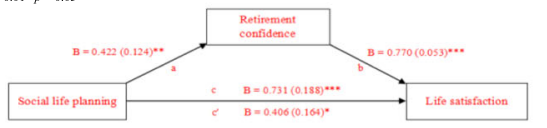

Indirect effect (ab) $=0.325, \mathrm{SE}=0.103, \mathrm{Cl} 95 \%=0.123$ to 0.529 ; Coefficients $(\mathrm{SE})$ of covariates age, gender, marital status, eductation, having children or not, and IADL were $0.023(0.023),-1.444(0.369)^{* *}$ $1.526(0.385)^{* * *}, 0.201000$

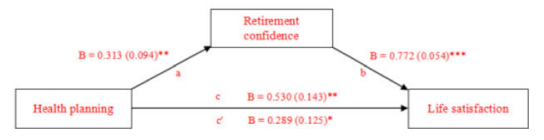

Indirect effect $(\mathrm{ab})=0.242, \mathrm{SE}=0.076, \mathrm{CI} 95 \%=0.101$ to 0.404 ; Coefficients (SE) of covariates age,
cender, marital status, education, having children or not, and IADL were $0.020(0.023),-1.567(0.367)^{* *}$, gender, marital status, education, having children or not, and IADL were $0.020(0.023),-1.567(0.367)^{* * *}$,
$1.597(0.386)^{* * *}, 0.260(0.082)^{* *}, 0.834(0.550)$, and $-0.095(0.119)$, respectively $; * * \mathrm{p}<0.001 * * p<$ $1.597(0.386)^{*} * 0$
$0.01 * p<0.05$

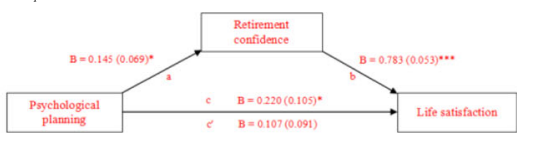

Indirect effect $(\mathrm{ab})=0.113, \mathrm{SE}=0.051, \mathrm{CI} 95 \%=0.019$ to 0.218 ; Cocfficients (SE) of covariates age, $594(0.388)^{* * *, 0.306}(0.082)^{* * *}, 0.903(0.554)$, and $-0.096(0.120)$, respectively; $* * * p_{p}<0.001 * * * ;$ $0.01 * p<0.05$

Fig. 4 Mediation of different domains of retirement planning and life satisfaction by retirement confidence

and/or indirectly through retirement confidence. Moreover, among the four planning subdomains, health, social life, and psychological planning were found to be correlated with improved post-retirement health and well-being through boosting retirement confidence levels. Retirement planning in financial domain was not found to be correlated with retirement confidence, but directly benefited life satisfaction in retirement.

Most studies on retirement planning have only measured it using a general item or have focused exclusively on financial planning (e.g., Elder and Rudolph 1999; Lusardi and Mitchell 2011). By comprehensively investigating different retirement planning activities, the present study fills this gap in the literature. The results revealed that, generally, aging adults in Hong Kong have performed insufficient retirement planning. Many of the retirees did not engage in any retirement planning activity. A government report on retirement planning revealed that $40 \%$ of future retirees had made no retirement preparation plans (Census and Statistics Department of Hong Kong 2013). Compared with the participants in the study conducted by Yeung (2013), who also investigated retirement planning in Hong Kong, the participants of the present study exhibited a lower level of retirement planning in each domain. This may be because the participants in Yeung's (2013) study were younger; the average age of the participants of the present study was 71.713 years. The participants in the current study may have not understood the importance of retirement planning when they retired over 10 years ago. Such a difference in results suggests that the younger generation of retirees is more aware of retirement planning and that they engage in more retirement planning activities. However, their level of preparation is still low.

The results also revealed that the participants were most likely to be involved in health planning activities, followed by psychological, financial, and social life planning. Compared with the male participants, the female participants displayed significantly higher levels of social life planning. This finding is consistent with that of a related study that reported that older women tend to participate in interactive activities, build strong friendship networks, and keep physically and socially active in their senior years (Consedine et al. 2005). The results of the present study also showed that the 
participants' retirement confidence scores in each domain were moderate, indicating that the retirees generally did not have confidence in their financial resources or in maintaining their health and cultivating retirement hobbies. This study identified the retirement planning domain to which older adults devote insufficient attention to as well as the specific retirement domains that they perceive as the most challenging. Thus, the findings revealed that public and workplace education on retirement planning should be improved, and that service providers should be aware of sex differences when designing retirement planning programs and services.

Based on longitudinal data, Noone et al. (2009) found that people who engaged in psychological planning (i.e., discussed retirement with their spouses) and financial planning (i.e., had superannuation or a savings plans) had greater retirement satisfaction and physical and psychological well-being. The present study supported such relationships between retirement planning and physical health, depressive symptoms, and life satisfaction among the retirees. The findings of the current study also support the proactive coping theory, which proposes that taking action in advance to prevent a potentially stressful event can effectively prevent adverse outcomes (Aspinwall and Taylor 1997). Moreover, as explained by continuity theory (Atchley 1989), retirement planning facilitates the continuation of previous living patterns, for example, achieving similar living standards through financial planning and maintaining a stable health status through health planning, which enable a smooth retirement transition. According to a local survey, over $50 \%$ of retirees in Hong Kong experience stress after retirement. Without retirement planning, older adults are more likely to develop depression (Chinese YMCA of Hong Kong 2016). The Hong Kong Government also advocates retirement planning as a crucial strategy for the future development of older adult services (Elderly Commission 2017) to enhance older adults' quality of life. In a recent longitudinal study, Cohen-Mansfield and Regev (2018) provided empirical support for the short-term value of retirement planning programs and the importance of developing follow-up programs to maintain short-term gains and to address the long-term developments of such programs.

The present study examined the relationships between the four subdomains of retirement planning as well as health and well-being outcomes and thus extends the findings in the literature. The results showed that all subdomains (expect financial planning) positively influenced physical health and life satisfaction through retirement confidence, and social life planning also had a significantly negative effect on depressive symptoms through retirement confidence. This finding supported self-efficacy theory (Bandura 1977). Therefore, people who had high retirement confidence felt more competent as a result of engaging in planning activities and would take further actions to produce more favorable retirement outcomes.

Unexpectedly, only financial planning failed to increase retirement confidence. People commonly believe that financial planning can reduce anxiety and increase confidence. However, this may not be true for older adults in Hong Kong. The current cohort was mostly engaged in labor-intensive work before retirement. With no savings or public retirement pensions, older adults may experience a sense of uncertainty and anxiety instead of mastery when they think about financial planning, which will outweigh the positive feelings associated with retirement planning. Nevertheless, financial planning can still directly benefit life 
satisfaction and is therefore valuable in retirement planning. Nongovernmental organizations and the private sector offer services and programs that promote retirement planning, but existing programs mainly focus on financial planning. As demonstrated in this study, various planning domains should be considered in retirement planning.

Both health and psychological planning significantly improve physical health and life satisfaction. Understandably, engaging in physical activities can contribute to a better health status, and thinking about and discussing retirement can help preretirees develop realistic expectations about retirement life. Moreover, retirement planning minimizes the negative impacts of retirement transition, such as role change and identity shift (Ashforth 2001; Taylor-Carter et al. 1997). In the present study, it is worth noting that the influence of psychological planning on life satisfaction was fully mediated by retirement confidence. To measure psychological planning, we determined whether the retirees discussed retirement with their spouse, relatives, friends, colleagues and whether they attended seminars. These preparations indicate a broad social network and access to formal and informal social support, which could be associated with better psychological health (Bai et al. 2018), and more confidence toward retirement life. Moreover, talking to a spouse or friend is related to the positive, action-oriented aspects of retirement planning (Noone et al. 2009), which is beneficial for a person to feel prepared for retirement.

In this study, social life planning was found to be the most beneficial but least planned domain. Social life planning is the only domain that can significantly contribute to better physical health, fewer depressive symptoms, and a higher level of life satisfaction. People's social networks inevitably shrink as they age. Cultivating a retirement hobby may help maintain a stable network and a similar lifestyle (Chong et al. 2006), which can contribute to a smooth retirement adaptation. A study conducted in Taiwan also found that free time management (e.g., setting goals and organizing leisure activities) had positive impact on quality of life among retirees (Wang et al. 2014). It has been increasingly recognized that retirement planning should not only consider the financial aspect but also an individual's interests and social life (e.g., Taylor-Carter et al. 1997; Yeung 2013; Yeung and Zhou 2017). Studies have also reported that leisure planning has a positive effect on anticipated retirement satisfaction and retirement self-efficacy (Taylor-Carter et al. 1997). Existing services and programs should be improved to raise future retirees' awareness about social life planning, including forming connections outside of work, socializing on a budget, engaging in volunteer work, joining groups, and pursuing multiple interests.

Several limitations of this study should be acknowledged. First, retrospective measures were used to collect information about preretirement experiences, which may cause some recalling bias and limited the establishment of causal relationships. Future studies are suggested to adopt a longitudinal research design and to more accurately capture the conditions both before and after retirement. Second, since few theories can be found to guide more hypotheses about gender differences, the discussion about the potentially different role of retirement planning and retirement confidence for older men and women is limited at current stage. However, the gender differences of older men's and women's retirement experiences do need more attention and discussion. It is suggested that scholars may conduct some qualitative studies in the future to explore the gender differences in older people's retirement experience and then test relevant theories with empirical evidence. 


\section{Conclusion}

This study is the first to examine and support the mediating effects of retirement confidence on the relationships between multiple domains of retirement planning and health and well-being outcomes. The crucial role of retirement planning, especially social life planning, reveals the need for the government and service providers to improve public education to raise future retirees' awareness of the importance of retirement planning. Moreover, the government and private sector should develop more comprehensive retirement planning programs, rather than only focusing on financial planning. The findings of this study have considerable policy implications for Hong Kong and other aging societies.

Acknowledgements We would like to thank all the participants in this study.

Author's Contributions CL conducted the data collection, data analysis and manuscript write-up and revision. XB contributed to the study conception and design and manuscript write-up. MK performed critical revisions of the manuscript. All authors have read and approved the manuscript.

Funding This work was supported by The Hong Kong Polytechnic University (Grant number: G-YBW3, G-UAEK, \& G-YBRW).

Data Availability The datasets generated during and/or analysed during the current study are available from the corresponding author on reasonable request.

\section{Compliance with Ethical Standards}

Conflict of Interest The authors declare that they have no competing interests.

Code Availability Not applicable.

Open Access This article is licensed under a Creative Commons Attribution 4.0 International License, which permits use, sharing, adaptation, distribution and reproduction in any medium or format, as long as you give appropriate credit to the original author(s) and the source, provide a link to the Creative Commons licence, and indicate if changes were made. The images or other third party material in this article are included in the article's Creative Commons licence, unless indicated otherwise in a credit line to the material. If material is not included in the article's Creative Commons licence and your intended use is not permitted by statutory regulation or exceeds the permitted use, you will need to obtain permission directly from the copyright holder. To view a copy of this licence, visit http://creativecommons.org/licenses/by/4.0/.

\section{References}

Ashforth, B. (2001). Role transitions in organizational life: An identity-based perspective. Mahwah: Lawrence Erlbaum.

Aspinwall, L. G., \& Taylor, S. E. (1997). A stitch in time: Self-regulation and proactive coping. Psychological Bulletin, 121(3), 417-436. https://doi.org/10.1037/0033-2909.121.3.417.

Atchley, R. C. (1989). A continuity theory of normal aging. The Gerontologist, 29, 183-190. https://doi.org/ 10.1093/geront/29.2.183.

Atchley, R. C. (1991). Social Forces and Aging (6th ed.). Belmont: Wadsworth. 
Bai, X., Yang, S. Y., \& Knapp, M. (2018). Sources and directions of social support and life satisfaction among solitary Chinese older adults in Hong Kong: The mediating role of sense of loneliness. Clinical Interventions in Aging, 13, 63-71. https://doi.org/10.2147/CIA.S148334.

Bandura, A. (1977). Self-efficacy: Toward a unifying theory of behavioral change. Psychological Review, 84(2), 191-215. https://doi.org/10.1037/0033-295X.84.2.191.

Bode, C., de Ridder, D. T., \& Bensing, J. M. (2006). Preparing for aging: Development, feasibility and preliminary results of an educational program for midlife and older based on proactive coping theory. Patient Education and Counseling, 61(2), 272-278. https://doi.org/10.1016/j.pec.2005.04.006.

Calasanti, T. M. (1996). Gender and life satisfaction in retirement: An assessment of the male model. The Journals of Gerontology Series B: Psychological Sciences and Social Sciences, 51(1), S18-S29. https:// doi.org/10.1093/geronb/51B.1.S18.

Census and Statistics Department (2013). Thematic Household Survey Report No. 52: Retirement planning and the financial situation in old age. Retrieved on June 16, 2018, from http://www.statistics.gov.hk/pub/ B11302522013XXXXB0100.pdf.

Census and Statistics Department (2015). Hong Kong Population Projections, 2015-2064. Published in September 2015. Retrieved on June 16, 2018, from http://www.statistics.gov.hk/pub/ B1120015062015XXXXB0100.pdf.

Census and Statistics Department (2016). Women and Men in Hong Kong Key Statistics. Retrieved on June 16, 2018, from http://www.statistics.gov.hk/pub/B11303032016AN16B0100.pdf.

Chinese YMCA of Hong Kong (2016). Over 50\% of Hong Kong Retirees Experience Stress After Retirement [press release]. Retrieved on June 17, 2018, from http:/www.ymca.org.hk/en/content/chinese-ymca\% E5\%85\%AC\%E5\%B8\%83\%E8\%AA\%BF\%E6\%9F\%A5-\%E9\%80\%BE\%E4\%BA\%94\%E6\%88\%90\% Е6\%B8\%AF\%E4\%BA\%BA\%Е9\%80\%80\%Е4\%BC\%91\%Е5\%BE\%8C\%Е6\%84\%9F\%Е5\%A3\%93\% E5\%8A\%9B.

Chong, A. M. L., Ng, S. H., Woo, J., \& Kwan, A. Y. H. (2006). Positive ageing: The views of middle-aged and older adults in Hong Kong. Ageing and Society, 26(2), 243-265. https://doi.org/10.1017/ S0144686X05004228.

Cohen-Mansfield, J., \& Regev, I. (2018). Retirement preparation programs: An examination of retirement perceptions, self-mastery, and well-being. Research on Social Work Practice, 28(4), 428-437. https://doi. org/10.1177/1049731516645194.

Consedine, N. S., Magai, C., \& Krivoshekova, Y. S. (2005). Sex and age cohort differences in patterns of socioemotional functioning in older adults and their links to physical resilience. Ageing International, 30, 209-244. https://doi.org/10.1007/s12126-005-1013-z.

Diener, E. D., Emmons, R. A., Larsen, R. J., \& Griffin, S. (1985). The satisfaction with life scale. Journal of Personality Assessment, 49(1), 71-75. https://doi.org/10.1207/s15327752jpa4901_13.

Elder, H. W., \& Rudolph, P. M. (1999). Does retirement planning affect the level of retirement satisfaction? Financial Services Review, 8(2), 117-127. https://doi.org/10.1016/S1057-0810(99)00036-0.

Elderly Commission (2017). Elderly services programme plan. Retrieved from http://www. elderlycommission.gov.hk/en/download/library/ESPP_Final_Report_Eng.pdf.

Fretz, B. R., Kluge, N. A., Ossana, S. M., Jones, S. M., \& Merikangas, M. W. (1989). Intervention targets for reducing preretirement anxiety and depression. Journal of Counseling Psychology, 36(3), 301-307. https://doi.org/10.1037/0022-0167.36.3.301.

Hayes, A. F. (2013). Model templates for PROCESS for SPSS and SAS. Retrieved 12 April, 2018, from http://www.personal.psu.edu/jxb14/M554/specreg/templates.pdf.

Hershey, D. A., Mowen, J. C., \& Jacobs-Lawson, J. M. (2003). An experimental comparison of retirement planning intervention seminars. Educational Gerontology, 29(4), 339-359. https://doi.org/10.1080/ 713844333.

IBM Corp. (2016). IBM SPSS statistics for windows, version 24.0 [Computer Program]. Armonk: IBM Corp.

Kim, J. E., \& Moen, P. (2002). Retirement transitions, gender, and psychological well-being: A life-course, ecological model. The Journals of Gerontology Series B: Psychological Sciences and Social Sciences, 57(3), 212-222. https://doi.org/10.1093/geronb/57.3.P212.

Kim, J., Kwon, J., \& Anderson, E. A. (2005). Factors related to retirement confidence: Retirement preparation and workplace financial education. Journal of Financial Counseling and Planning, 16(2), 77-89.

Kosloski, K., Ekerdt, D., \& DeViney, S. (2001). The role of job-related rewards in retirement planning. The Journals of Gerontology Series B: Psychological Sciences and Social Sciences, 56(3), 160-169. https:// doi.org/10.1093/geronb/56.3.P160.

Larsen, M. (2008). Does quality of work life affect men and women's retirement planning differently? Applied Research in Quality of Life, 3(1), 23-42. 
Law, K. W. K., Wan, P., \& Wong, T. K. Y. (2006). Retirement planning. In S. W. Leung, P. Wan, \& S. L. Wong (Eds.), Indicators of social development Hong Kong (pp. 157-185). Hong Kong: Hong Kong Institute of Asia-Pacific Studies, Chinese University of Hong Kong.

Lawton, M. P., \& Brody, E. M. (1969). Assessment of older people: Self-maintaining and instrumental activities of daily living. The Gerontologist, 9(3), 179-186. https://doi.org/10.1093/geront/9.3_Part_1. 179.

Lee, W. K. M., \& Law, K. W. K. (2004). Retirement planning and retirement satisfaction: The need for a national retirement program and policy in Hong Kong. Journal of Applied Gerontology, 23(3), 212-233. https://doi.org/10.1177/0733464804268591.

Leung, D. Y. P., Leung, A. Y. M., \& Chi, I. (2011). An evaluation of the factor structure of the instrumental activities of daily living involvement and capacity scales of the minimum data set for home care for elderly Chinese Community Dwellers in Hong Kong. Home Health Care Services Quarterly 30(3), 147159.

Lusardi, A., \& Mitchell, O. S. (2011). Financial literacy and retirement planning in the United States. Journal of Pension Economics and Finance, 10(4), 509-525. https://doi.org/10.1017/S147474721100045X.

Mallinckrod, B., Abraham, W. T., Wei, M., \& Russell, D. W. (2006). Advances in testing the statistical significance of mediation effects. Journal of Counseling Psychology, 53(3), 372-378. https://doi.org/10. 1037/0022-0167.53.3.372.

Midanik, L. T., Soghikian, K., Ransom, L. J., \& Tekawa, I. S. (1995). The effect of retirement on mental health and health behaviors: The Kaiser Permanente retirement study. The Journals of Gerontology Series B: Psychological Sciences and Social Sciences, 50(1), S59-S61. https://doi.org/10.1093/geronb/50B.1. S59.

Mutran, E. J., Reitzes, D. C., \& Fernandez, M. E. (1997). Factors that influence attitudes toward retirement. Research on Aging, 19(3), 251-273. https://doi.org/10.1177/0164027597193001.

Noone, J. H., Stephens, C., \& Alpass, F. M. (2009). Preretirement planning and well-being in later life: A prospective study. Research on Aging, 31(3), 295-317. https://doi.org/10.1177/0164027508330718.

Quick, H. E., \& Moen, P. (1998). Gender, employment and retirement quality: A life course approach to the differential experiences of men and women. Journal of Occupational Health Psychology, 3(1), 44-64. https://doi.org/10.1037/1076-8998.3.1.44.

Reitzes, D. C., \& Mutran, E. J. (2004). The transition to retirement: Stages and factors that influence retirement adjustment. The International Journal of Aging and Human Development, 59(1), 63-84. https://doi.org/ 10.2190/NYPP-RFFP-5RFK-8EB8.

Rinaldi, P., Mecocci, P., Benedetti, C., Ercolani, S., Bregnocchi, M., Menculini, G, ... \& Cherubini, A. (2003). Validation of the five-item geriatric depression scale in elderly subjects in three different settings. Journal of the American Geriatrics Society, 51(5), 694-698. https://doi.org/10.1034/j.1600-0579.2003. 00216.x.

Ross, C. E., \& Drentea, P. (1998). Consequences of retirement activities for distress and the sense of personal control. Journal of Health and Social Behavior, 39, 317-334. https://doi.org/10.2307/2676341.

Schellenberg, G. (2004). The retirement plans and expectations of non-retired Canadians aged 45 to 59. Statistics Canada, Business and Labour Market Analysis Division.

Sun, P., Wang, S., \& Kong, F. (2014). Core self-evaluations as mediator and moderator of the relationship between emotional intelligence and life satisfaction. Social Indicators Research, 118(1), 173-180. https:// doi.org/10.1007/s11205-013-0413-9.

Taylor-Carter, M. A., Cook, K., \& Weinberg, C. (1997). Planning and expectations of the retirement experience. Educational Gerontology: An International Quarterly, 23(3), 273-288. https://doi.org/10. 1080/0360127970230306.

Tong, A. Y., \& Man, D. W. (2002). The validation of the Hong Kong Chinese version of the Lawton instrumental activities of daily living scale for institutionalized elderly persons. OTJR: Occupation, Participation and Health, 22(4), 132-142. https://doi.org/10.1177/153944920202200402.

Wang, M. (2007). Profiling retirees in the retirement transition and adjustment process: Examining the longitudinal change patterns of retirees' psychological well-being. Journal of Applied Psychology, 92(2), 455-474. https://doi.org/10.1037/0021-9010.92.2.455.

Wang, M., \& Shultz, K. S. (2010). Employee retirement: A review and recommendations for future investigation. Journal of Management, 36(1), 172-206. https://doi.org/10.1177/0149206309347957.

Wang, W. C., Wu, C. Y., \& Wu, C. C. (2014). Free time management makes better retirement: A case study of retirees' quality of life in Taiwan. Applied Research in Quality of Life, 9(3), 591-604.

Yeung, D. Y. (2013). Is pre-retirement planning always good? An exploratory study of retirement adjustment among Hong Kong Chinese retirees. Aging and Mental Health, 17(3), 386-393. https://doi.org/10.1080/ 13607863.2012 .732036 . 
Yeung, D. Y., \& Zhou, X. (2017). Planning for retirement: Longitudinal effect on retirement resources and post-retirement well-being. Frontiers in Psychology, 8, 1300. https://doi.org/10.3389/fpsyg.2017.01300.

Publisher's Note Springer Nature remains neutral with regard to jurisdictional claims in published maps and institutional affiliations.

\section{Affiliations}

\section{Chang $\mathrm{Liu}^{1} \cdot$ Xue Bai ${ }^{1,2} \cdot$ Martin Knapp ${ }^{3,4}$}

1 Department of Applied Social Sciences, The Hong Kong Polytechnic University, Hong Kong, China

2 Institute of Active Ageing, The Hong Kong Polytechnic University, Hong Kong, China

3 Department of Health Policy, The London School of Economics and Political Science, London, UK

4 Care Policy and Evaluation Centre, The London School of Economics and Political Science, London, UK 